\title{
Hybridization between white-headed ducks and introduced ruddy ducks in Spain
}

\author{
V. MUÑOZ-FUENTES,${ }^{*}+$ C. VILÀ,, A. J. GREEN,${ }^{*}$ J. J. NEGRO* and M. D. SORENSON \\ *Estación Biológica de Doñana (CSIC), Avda. María Luisa s/n, E-41013 Sevilla, Spain, +Department of Evolutionary Biology, Uppsala \\ University, SE-75236 Uppsala, Sweden, $\ddagger$ Department of Biology, Boston University, 5 Cummington Street, Boston, MA 02215, USA
}

\begin{abstract}
The ruddy duck, Oxyura jamaicensis, was introduced to Great Britain in the mid-20th century and has recently spread to other Western European countries. In Spain, ruddy ducks hybridize with the globally endangered white-headed duck, Oxyura leucocephala. We assessed the effects of hybridization on the Spanish white-headed ducks, which constitute $25 \%$ of the global population of this species, using a panel of eight nuclear intron markers, 10 microsatellite loci, and mtDNA control region sequences. These data allowed parental individuals, $\mathrm{F}_{1}$ hybrids, and the progeny of backcrossing to be reliably distinguished. We show that hybrids between the two species are fertile and produce viable offspring in backcrosses with both parental species. To date, however, we found no extensive introgression of ruddy duck genes into the Spanish white-headed duck population, probably due to the early implementation of an effective ruddy duck and hybrid control programme. We also show that genetic diversity in the expanding European ruddy duck population, which was founded by just seven individuals, exceeds that of the native Spanish white-headed duck population, which recently recovered from a severe bottleneck. Unless effective control of ruddy ducks is continued, genetic introgression will compromise the unique behavioural and ecological adaptations of white-headed ducks and consequently their survival as a genetically and evolutionary distinct species.
\end{abstract}

Keywords: hybridization, introns, microsatellites, mitochondrial DNA, Oxyura, white-headed duck

\section{Introduction}

Human activities have resulted in the extension of certain species' native geographical ranges or introductions to new areas, which in turn have led to hybridization with native plant and animal species, often with significant negative consequences (e.g. Kanda et al. 2002; Moody \& Less 2002). Hybridization is common in birds, and particularly among waterfowl (Grant \& Grant 1992). Hybridization between mallards Anas platyrhynchos and several closely related species has resulted from introductions of mallards or shifting geographical ranges. The Hawaiian duck (Anas wyvilliana, Browne et al. 1993) and New Zealand grey ducks (Anas superciliosa superciliosa, Gillespie 1985; Rhymer et al. 1994) have suffered from extensive hybridization with introduced mallards, whereas continental mallard populations hybridize

Correspondence: V. Muñoz-Fuentes, Fax: +46(0) 18471 6310; E-mail: violeta.munoz@ebc.uu.se with black ducks (Anas rubripes, Mank et al. 2004) and mottled ducks (Anas fulvigula, McCracken et al. 2001; Williams et al. 2005) in North America, and eastern spot-billed, Anas zonorhyncha, in Russia (Kulikova et al. 2004). The production of hybrid individuals, however, does not necessarily imply genetic introgression between species. Hybrid individuals may be infertile or have low fitness due to reduced survival and/or reproductive success (Liou \& Price 1994; Coyne \& Orr 2004). In birds, incomplete prezygotic and postzygotic isolation are common. Particularly in waterfowl, hybrids are often fertile (Grant \& Grant 1992; Price \& Bouvier 2002), but occur infrequently in most natural populations, making introgression unlikely. Therefore, identification of hybrids as well as information on their fertility and reproduction in the wild is crucial to assessing the impact of hybridization on a species.

The white-headed duck is the only stifftail duck (subfamily Oxyurinae) native to the Palaearctic and is classified as Endangered by the IUCN (BirdLife International 2000). 
Although white-headed ducks had a wide distribution in the past, extending from Spain and Morocco in the west to the western limit of China in the east, populations became fragmented and suffered major declines in recent decades (Green \& Hughes 2001). After extinctions in Egypt, Central and Eastern Europe, and Asia, extant populations have become isolated from each other (Green \& Hughes 2001; Li \& Mundkur 2003). The largest population in the western half of the species' range is in Spain, and it is the only population that has been growing in recent decades. Only 22 individuals were counted in 1977 (Torres \& Moreno-Arroyo 2000a), but the population has since recovered and appears to have stabilized at about 2500 birds (Hughes et al. 2004), constituting about $25 \%$ of the current world population. This successful recovery, however, has been marred by the arrival in Spain of the North American ruddy duck.

Seven ruddy ducks were imported to a zoological collection in England in 1948 and during subsequent years approximately 90 of their descendants escaped to the wild (Hudson 1976). As the feral ruddy duck population increased in Great Britain, it expanded to other Western European countries and Morocco (Hughes et al. 2004), thus invading the white-headed duck's range [see Muñoz-Fuentes et al. (2005a), Brua (2001), and Hughes (1997) for more information on the geographical ranges of the two species]. In 1984, ruddy ducks numbered 2000 in the UK alone (Collier et al. 2005) and were detected in Spain for the first time (Torres \& Moreno-Arroyo 2000b). The first ruddy duck $\times$ white-headed duck hybrid was identified in 1991 (Torres \& Moreno-Arroyo 2000b), contributing to concerns for the white-headed duck that have prompted efforts to eliminate feral ruddy ducks in Portugal, Spain, France and the UK. Hybridization and up to two generations of backcrossing have been observed in captivity (B. Hughes, unpublished) but the degree of genetic introgression and patterns of hybridization in the wild are unknown.

In this study, we used a panel of molecular genetic markers to (i) confirm that ruddy ducks and white-headed ducks are two well-differentiated species; (ii) compare the genetic diversity of their populations; (iii) determine the parentage of suspected hybrid individuals; and (iv) assess the degree of genetic introgression between the two species in Spain. Our data set includes mitochondrial DNA (mtDNA), 10 nuclear microsatellite loci derived from parallel genomic libraries for Spanish ruddy ducks and white-headed ducks, and fixed differences in nuclear introns. These diagnostic markers in combination with microsatellite data allowed the discrimination of $\mathrm{F}_{1}$ and subsequent generation hybrids, categories that may be difficult to discriminate with microsatellite data alone (Vähä \& Primmer 2006), and therefore allowed us to test for successful reproduction of hybrid individuals. Information on mtDNA haplotypes also allowed inferences about potential asymmetries in the composition of hybrid pairs and fertility of different hybrid classes.

\section{Materials and methods}

\section{Samples}

Our analyses were based on 31 ruddy ducks, 63 whiteheaded ducks and 29 presumed hybrids collected between 1993 and 2003 across Spain. Samples from white-headed ducks were obtained from individuals found dead in the field, except for seven individuals ringed, sampled and released in 2003. Ruddy duck and hybrid samples were obtained from animals shot as part of the ongoing eradication programme. Initial identification of each individual was based on morphology, mainly plumage characteristics and beak shape (Urdiales \& Pereira 1993), and was completed by ornithologists familiar with these species prior to the genetic analysis.

In hybridization studies, it is essential to compare the genetic composition of the species of interest with allopatric individuals of the same species, i.e. collected in areas free of hybridization. Therefore, to identify species-specific alleles, we used ruddy ducks collected between 1987 and 2003 from areas in Europe where they do not co-exist with white-headed ducks (England, France, Iceland and two captive-bred populations) and from North America (for microsatellite markers, ruddy duck populations are not differentiated across Europe, but they are significantly differentiated from North American ruddy ducks; MuñozFuentes et al. 2006), and white-headed ducks from Greece and a captive population in Spain (El Acebuche, Doñana National Park). This latter captive population was established before ruddy ducks were recorded in Spain and is therefore free of introgression. Tissues included blood, brain, muscle and feathers. DNA was extracted as described in Muñoz-Fuentes et al. (2005a).

\section{Sequencing of the mtDNA control region}

For all hybrids, and a sample of 27 ruddy ducks and 43 white-headed ducks, we determined mtDNA haplotypes. In previous studies, we sequenced $575 \mathrm{bp}$ of the mtDNA control region for both ruddy ducks and white-headed ducks using primers L81 and H768 (Muñoz-Fuentes et al. 2005a, 2006). Based on these data, we designed speciesspecific primers to selectively amplify the mtDNA of one species but not the other, allowing the maternal line of additional individuals to be identified with a simple polymerase chain reaction (PCR) test. Each sample was tested with OXJA.CRF1 (5'-CATAYCATGCTCCCAACCATAC-3') and OXJA.CRR1 (5'-TTCACGTGAGGTGTACGGCT-3') for ruddy duck mtDNA and OXLE.CRF1 (5'-CATGCTCCCAACCATAACCA-3') and H493 (Sorenson \& Fleischer 1996) for white-headed duck mtDNA. DNA was amplified in $25-\mu \mathrm{L}$ reactions as in Muñoz-Fuentes et al. (2005a). PCRs were performed in a GeneAmp PCR System 
9700 (Applied Biosystems) thermocycler: one segment of $95^{\circ} \mathrm{C}$ for $6 \mathrm{~min} ; 25$ cycles of $95^{\circ} \mathrm{C}$ for $20 \mathrm{~s}, 60^{\circ} \mathrm{C}$ for $20 \mathrm{~s}$, and $72{ }^{\circ} \mathrm{C}$ for $1 \mathrm{~min}$; and a final segment of $72{ }^{\circ} \mathrm{C}$ for $7 \mathrm{~min}$. Presence or absence of amplification was visualized under UV light in $2 \%$ agarose with ethidium bromide. Thus, for the Spanish sample, sequence data were available for $n=24$ putative hybrids, $n=12$ white-headed ducks, and $n=1$ ruddy duck, whereas mtDNA haplotypes of the remaining individuals $[n=5$ putative hybrids (all 5 had ruddy duck mtDNA), 31 white-headed ducks, and 26 ruddy ducks] was assigned to species using the PCR test. We encountered no evidence of nuclear pseudogenes.

\section{Typing of nuclear introns}

Fixed differences in introns from eight different nuclear genes were identified for a sample of ruddy ducks and whiteheaded ducks (Table 1). These introns were phosphoenolpyruvate carboxykinase, intron 9 (PEPCK9); tropomyosin, intron 5 (Trop); lactate dehydrogenase-B, intron 3 (LDHB); myelin proteolipid protein, intron 4 (MPP); 5-aminolevulinate synthase, intron 8 (ALSY); $\alpha$-enolase, intron 8 (ENOL); transforming growth factor- $\beta 2$, intron 5 (TGFb2); rhodopsin, intron 1 (RHDP). These eight loci were among 18 that we tested for fixed differences between the species (see Table S1, Supplementary material, for 10 additional loci for which either amplification or sequencing was unsuccessful, or for which there were no fixed differences). Many of the loci have been used in previous studies (e.g. Friesen et al. 1997; Pacheco et al. 2002; Primmer et al. 2002), but we downloaded sequences from GenBank and designed our own primers based on alignments of chicken (Gallus gallus), mallard (Anas platyrhynchos), and selected mammals, as available (see Table S1 for primer sequences). Primers were placed in the exons flanking each intron. For each intron, we obtained sequences for allopatric white-headed ducks and ruddy ducks; ruddy ducks from England or France and whiteheaded ducks from Greece or the captive population at El Acebuche, Doñana National Park.

Depending on the nature of the difference, we then designed assays to genotype the diagnostic polymorphic base at each locus (Table 1). First, if a fixed difference resulted in a restriction site difference between the two species (four of eight loci), we digested PCR products with the appropriate restriction enzyme and then determined genotypes from the presence or absence of restriction fragments in an agarose gel. For one locus with a transversion difference between the two species (PEPCK9), we designed species-specific primers with the $3^{\prime}$ base on the polymorphic site and visualized the presence or absence of amplification in an agarose gel. In the case of another locus (Trop), sequences of the two species differed in length by $13 \mathrm{bp}$, due to two indels of 5 and $8 \mathrm{bp}$ each, such that the difference in size of PCR products could be visualized in an

Table 1 Primers used for genotyping nuclear intron loci with fixed differences between ruddy ducks and white-headed ducks. Intron number, Primer names, sequences, annealing temperature and allele detection method are indicated for each locus. F, forward primer; R, reverse primer; $\mathrm{S}, \mathrm{SNaPshot}$ primer; $T_{\mathrm{a}^{\prime}}$ annealing temperature; $\mathrm{RE}$, restriction enzyme

\begin{tabular}{|c|c|c|c|c|c|}
\hline Locus name & Intron & Primer names & Primer sequence $\left(5^{\prime}-3^{\prime}\right)$ & $T_{\mathrm{a}}\left({ }^{\circ} \mathrm{C}\right)$ & Detection method \\
\hline Alpha enolase (Enol, E) & 8 & $\begin{array}{l}\text { OXY.Enol.8F } \\
\text { OXY.Enol.8R }\end{array}$ & $\begin{array}{l}\text { F: AAGTCCTTCAACATGCAGCCTCC } \\
\text { R: CATGCAGCACATTGCTAACCCTG }\end{array}$ & 55 & RE (Hpy 188I)† \\
\hline $\begin{array}{l}\text { 5-aminolevulinate } \\
\text { synthase (Alsy, A) }\end{array}$ & 8 & $\begin{array}{l}\text { OXY.ALSY.8F } \\
\text { ALSY.9R }\end{array}$ & $\begin{array}{l}\text { F: CTGTTTAGTGGGCACAAGGAAG } \\
\text { R: TCTGTATTTTTAGCAGCATCTGC }\end{array}$ & 55 & $\mathrm{RE}(\mathrm{BspHI}) \ddagger$ \\
\hline Rhodopsin (RHDP, R) & 1 & $\begin{array}{l}\text { RHDP.1F } \\
\text { OXY.RHDP.1R }\end{array}$ & $\begin{array}{l}\text { F: TTTGTCTTTGGAGTAACAGGGTG } \\
\text { R: CAGCACTGCAACTGCCTCAGC }\end{array}$ & 55 & RE (Fnu 4HI)‡ \\
\hline $\begin{array}{l}\text { Transforming growth } \\
\text { factor-beta2 (TGFb2, G) }\end{array}$ & 5 & $\begin{array}{l}\text { OXY.TGFb2.5F } \\
\text { OXY.TGFb2.5R }\end{array}$ & $\begin{array}{l}\text { F: GACCTTAGAAAGCAGAGACTGAGC } \\
\text { R: GCTTATATCAAGCTAATGGTTTTCC }\end{array}$ & 55 & RE (HaeIII) $\ddagger$ \\
\hline Tropomyosin (Trop, T) & 5 & $\begin{array}{l}\text { Trop.5F } \\
\text { Ox.Trop.1R }\end{array}$ & $\begin{array}{l}\text { F: GAGTTGGAYCGNGCYCAGGAGCG } \\
\text { R: CTCTGACCTCCAAAACACATTAGCACAC }\end{array}$ & 55 & Length difference \\
\hline $\begin{array}{l}\text { Phosphoenolpyruvate } \\
\text { carboxykinase (PEPCK9, P) }\end{array}$ & 9 & $\begin{array}{l}\text { OxLe.PEPCK } \\
\text { PEPCK.9R* } \\
\text { OxJa PEPCK } \\
\text { PEPCK 9R1 }\end{array}$ & $\begin{array}{l}\text { F: GTGCTATTTATTCCTTAACGTTCTCCA } \\
\text { R: GTGCCATGCTAAGCCAGTGGG } \\
\text { F: CTATTTATTTCTTAACGTCCTCCTTTG } \\
\text { R: GTGCCATGCTAAGCCAGTGGG }\end{array}$ & $\begin{array}{l}60 \\
60\end{array}$ & PCR success/failure \\
\hline $\begin{array}{l}\text { Lactate dehydrogenase-B } \\
(\text { LDHB, L) }\end{array}$ & 3 & $\begin{array}{l}\text { LDHB.3F* } \\
\text { LDHB.Oxy.4R2 } \\
\text { LDHB.Oxy.SNP }\end{array}$ & $\begin{array}{l}\text { F: GAAGAYAARCTNAARGGRGAAATGATGGA } \\
\text { R: GCTTGAATTGAGAACCATTCCC } \\
\text { S: ACTGATGTTATYGGGACTCAGGA }\end{array}$ & 55 & Single-base extension \\
\hline $\begin{array}{l}\text { Myelin proteolipid } \\
\text { protein }(\mathrm{MPP}, \mathrm{M})\end{array}$ & 4 & $\begin{array}{l}\text { OXY.MPP.4F } \\
\text { OXY.MPP.4R } \\
\text { MPP.Oxy.SNP }\end{array}$ & $\begin{array}{l}\text { F: CTGTGTGCGGACGCCAGGA } \\
\text { R: TTCCAGGGCAGGACGCCTG } \\
\text { S: CTCTGTGCCCCRTCTCAC }\end{array}$ & 55 & Single-base extension \\
\hline
\end{tabular}

*McCracken and Sorenson (2005); †, cuts white-headed duck allele; $\ddagger$, cuts ruddy duck allele. 
agarose gel. Finally, when none of these methods could be applied (LDHB, MPP), we used a single-base extension technique, the SNaPshot kit (Applied Biosystems), for which we designed internal SNaPshot primers (Table 1), allowing the species-specific base to be identified by fluorescence in an automatic sequencer.

PCRs were carried out in $20-\mu \mathrm{L}$ reactions containing $1 \times$ Gold Buffer (Applied Biosystems), $2.5 \mathrm{~mm} \mathrm{MgCl}, 1 \mathrm{~mm}$ dNTPs $(0.25 \mathrm{~mm}$ each), $0.5 \mu \mathrm{M}$ forward primer, $0.5 \mu \mathrm{M}$ reverse primer, $25-100 \mathrm{ng}$ of genomic DNA and $0.7 \mathrm{U}$ of AmpliTaq Gold DNA polymerase (Applied Biosystems). PCRs were performed in a GeneAmp PCR System 9700 (Applied Biosystems) or PTC-100 Programmable Thermal Controller (MJ Research) using the following conditions: one segment of $95^{\circ} \mathrm{C}$ for $6 \mathrm{~min} ; 35$ cycles of $95^{\circ} \mathrm{C}$ for $45 \mathrm{~s}$, $55^{\circ} \mathrm{C}$ or $60^{\circ} \mathrm{C}$ (depending on primers; see Table 1) for $30 \mathrm{~s}$, and $72{ }^{\circ} \mathrm{C}$ for $1 \mathrm{~min}$; and a final segment of $72{ }^{\circ} \mathrm{C}$ for $7 \mathrm{~min}$. In the case of PEPCK9, the number of PCR cycles was set to 30. Restriction digests were in $10-\mu \mathrm{L}$ reactions with $4 \mu \mathrm{L}$ of PCR product, 3.5 $\mathrm{U}$ of restriction enzyme and the appropriate buffer (New England Biolabs). This was incubated at $37^{\circ} \mathrm{C}$ for $1 \mathrm{~h}$ and the resulting product visualized in $2 \%$ agarose. For PEPCK9 and Trop, the PCR product was directly visualized in $2 \%$ agarose. For $\mathrm{SNaPshot} \mathrm{reactions,}$ $5 \mu \mathrm{L}$ of PCR product was prepared by incubating with $1 \mu \mathrm{L}$ of ExoSAP-IT (Amersham Biosciences) at $37^{\circ} \mathrm{C}$ for $15 \mathrm{~min}$ and $80^{\circ} \mathrm{C}$ for $15 \mathrm{~min}$. Single-base extensions were in $10-\mu \mathrm{L}$ extension reactions with $2 \mu \mathrm{L}$ SNaPshot Ready Reaction Mix (Applied Biosystems), pooled PCR products for two loci $(1 \mu \mathrm{L}$ each) and pooled SNaPshot primers $(0.06 \mu \mathrm{M}$ of LDHB.Oxy.SNP and $0.1 \mu \mathrm{M}$ of MPP.Oxy.SNP). Cycling conditions were 25 cycles of $96^{\circ} \mathrm{C}$ for $10 \mathrm{~s}, 50^{\circ} \mathrm{C}$ for $5 \mathrm{~s}$, and $60{ }^{\circ} \mathrm{C}$ for $30 \mathrm{~s}$. We used Sephadex G-50 fine to remove unincorporated ddNTPs, and then reaction products were electrophoresed in an ABI PRISM 3100 automated sequencer (Applied Biosystems).

We tested these eight assays on a larger panel of 33 feral European ruddy ducks and 52 wild and captive whiteheaded ducks from Spain. The results support the conclusion that Spanish white-headed ducks and European ruddy ducks are fixed for alternative alleles at each of these loci. We also tested the performance of our methods with five captive-bred hybrids of known origin (three $\mathrm{F}_{1}$ s, one backcross to a white-headed duck and one backcross to a ruddy duck). Genotypes were concordant with expectations given the crosses that produced these birds, indicating that our assays allowed accurate determination of the genotypes of wild hybrids.

\section{Typing of microsatellite alleles}

We scored all individuals for 10 microsatellite loci developed specifically for these two Oxyura species (Muñoz-Fuentes et al. 2005b, 2006). Five loci from each species were derived from approximately equal numbers of candidate loci in each species (Muñoz-Fuentes et al. 2005b), thereby controlling for the ascertainment bias typically encountered in interspecific comparisons; polymorphism is often greater in the species from which a microsatellite locus is derived (Ellegren et al. 1995; Wright et al. 2004). The Spanish sample included birds that were morphologically identified as ruddy ducks $(n=31)$, white-headed ducks $(n=63)$ and hybrids $(n=29)$. Microsatellite data for white-headed ducks in allopatry were obtained for birds from Greece $(n=6)$ and the captive population in Spain $(n=19)$. Ruddy duck microsatellite data for birds in allopatry were obtained for individuals from France $(n=18)$, the UK $(n=27)$, two captive populations in the UK ( $n=6$ and 7) and North America $(n=51)$ (Muñoz-Fuentes et al. 2006). Microsatellite allele frequencies in the reference populations are provided as Supplementary material (Table S2).

\section{Data analysis}

We tested the microsatellite data for Hardy-Weinberg equilibrium and linkage disequilibrium with GENEPOP (Raymond \& Rousset 1995) and we applied Bonferroni sequential correction (Rice 1989) to evaluate statistical significance when multiple simultaneous tests are performed. We checked for genotyping errors with MICROCHECKER version 2.2.1 (Van Oosterhout et al. 2004). One additional locus, Oxy4, was also typed but excluded from the analyses because it did not conform to Hardy-Weinberg expectations in ruddy ducks, and there was evidence for linkage disequilibrium in both ruddy ducks (Muñoz-Fuentes et al. 2006) and white-headed ducks.

We used a factorial correspondence analysis (FCA) as implemented in GENETIX version 4.05.2 (Belkhir et al. 19962004) to plot each individual in a two-dimensional space according to their microsatellite and intron allele composition independent of any a priori species designations. We used HP-RARE 1.0 (Kalinowski 2005) to correct allelic richness values for differences in sample size. One marker, Oxy14, was included for genetic diversity calculations, but dropped from subsequent analyses due to evidence of preferential amplification of the white-headed duck allele in hybrids (see Results).

We also used a Bayesian assignment method, as implemented in the software NEWHYBRIDS version 1.1 beta (Anderson \& Thompson 2002), to identify pure individuals and distinguish among hybrid types. This approach makes no a priori assumptions about population allele frequencies. We ran NEWHYBRIDS for all individuals collected in Spain (presumed white-headed ducks, ruddy ducks and hybrids) and set the program to distinguish the two parental species, $\mathrm{F}_{1} \mathrm{~s}, \mathrm{~F}_{2} \mathrm{~s}$, and first-generation backcrosses to each of the parental species six categories: We repeated the analysis with the program set to also recognize second-generation 
backcrosses (eight categories). Some of the individuals identified as the progeny of backcrosses in the first analysis were assigned a low to moderate probability of being the result of second-generation backcrosses (Table S3, Supplementary material), but these probabilities varied depending on the priors used, suggesting that our data were not sufficient to unambiguously distinguish first- and secondgeneration backcrosses.

\section{Results}

\section{Genetic diversity and divergence}

The mtDNA control region sequences of white-headed ducks and ruddy ducks are unambiguously distinguished by 18 fixed differences or $\sim 3 \%$ sequence divergence (Table 54 , Supplementary material). A single haplotype was detected in the ruddy duck population all over Europe (MuñozFuentes et al. 2006), whereas three closely related whiteheaded duck haplotypes (maximum sequence divergence of $0.2 \%$ ) are present in Spain (Muñoz-Fuentes et al. 2005a). At 7 of 10 microsatellite loci, white-headed ducks and ruddy ducks in Spain had no alleles in common (Table S2). At the remaining loci, alleles shared with ruddy ducks were also present in white-headed ducks from Greece and the captive white-headed duck population. Likewise, at the eight intron markers, no ruddy duck alleles were detected in birds morphologically identified as white-headed ducks. Thus, there was no evidence for introgression of ruddy duck alleles into the Spanish white-headed duck population.

Based on microsatellite data, expected and observed heterozygosities $( \pm S D)$ were $0.363 \pm 0.080$ and $0.310 \pm 0.027$, respectively, in ruddy ducks; and $0.183 \pm 0.067$ and $0.188 \pm$ 0.016 in white-headed ducks (Table 2). In addition, the total number of alleles in ruddy ducks $(n=32$ in 30 individuals) was more than twice as large as in white-headed ducks ( $n=15$ in 63 individuals). Multilocus genotypes in 36 of 59 (61\%) white-headed ducks with complete data were identical to at least one other individual; and up to eight individuals shared the same genotype. In contrast, each

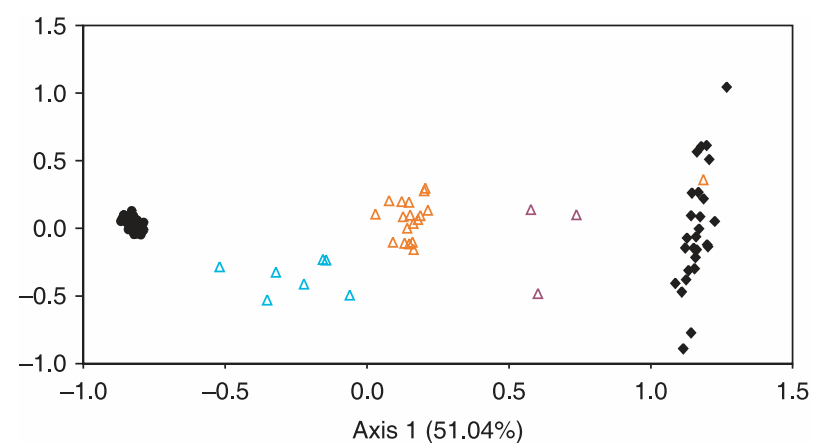

Fig. 1 Two-dimensional factorial correspondence analysis of multilocus genotypes based on microsatellite and intron data. Birds were identified morphologically as white-headed ducks (circles), ruddy ducks (diamonds) or hybrids (triangles). Subsequent analyses of hybrid genotypes (Fig. 2) enabled their classification into different hybrid types. Each colour represents a hybrid category as shown in Fig. 2.

ruddy duck in Spain had a unique multilocus genotype. A factorial correspondence analysis of the microsatellite and intron data (Fig. 1) reflects substantial differentiation between the two species at nuclear loci $\left(F_{\mathrm{ST}}=0.74 ; P<\right.$ $0.001)$ and lower genetic diversity in white-headed ducks than in ruddy ducks. The factorial correspondence analysis also showed that all but one of the individuals identified as hybrids based on morphology occupied an intermediate position between white-headed ducks and ruddy ducks (Fig. 1).

\section{Hybrid identification and type of crosses}

One microsatellite marker, Oxy14, was included for genetic diversity calculations of ruddy ducks and white-headed ducks but dropped from subsequent analyses in NEWHYBRIDS due to evidence of preferential amplification of whiteheaded duck alleles in hybrids. Individuals 21, 22, 23, 24 and 25 tested as homozygous for allele 131 at locus Oxy14 (these individuals were genotyped twice to confirm this result), but were heterozygous with one allele coming

Table 2 Genetic variability in white-headed ducks and ruddy ducks

\begin{tabular}{|c|c|c|c|c|c|c|c|c|c|}
\hline \multirow[b]{2}{*}{ Population } & \multicolumn{4}{|c|}{ Mitochondrial DNA } & \multicolumn{5}{|c|}{ Microsatellites } \\
\hline & $n$ & No. hapl. & $\mathrm{Hd} \pm \mathrm{SD}$ & $\pi \pm \mathrm{SD}$ & $n$ & $\mathrm{AR}$ & $\mathrm{AR}_{\mathrm{C}}$ & $H_{\mathrm{E}} \pm \mathrm{SD}$ & $H_{\mathrm{O}} \pm \mathrm{SD}$ \\
\hline Spanish white-headed ducks & 39 & $2^{*}$ & $0.456 \pm 0.053$ & $0.0024 \pm 0.0003$ & 63 & 1.5 & 1.5 & $0.183 \pm 0.067$ & $0.188 \pm 0.016$ \\
\hline Spanish ruddy ducks & 13 & 1 & 0.000 & 0.000 & 30 & 3.2 & 3.2 & $0.363 \pm 0.080$ & $0.310 \pm 0.027$ \\
\hline European ruddy duckst & 34 & 1 & 0.000 & 0.000 & 78 & 3.4 & 3.0 & $0.369 \pm 0.080$ & $0.363 \pm 0.017$ \\
\hline North American ruddy ducks & 67 & 23 & $0.824 \pm 0.044$ & $0.0035 \pm 0.0003$ & 51 & 6.3 & 5.4 & $0.488 \pm 0.088$ & $0.443 \pm 0.022$ \\
\hline
\end{tabular}

$n$, sample size, number of individuals; No. hapl., number of haplotypes; Hd, haplotype diversity; $\pi$, nucleotide diversity; SD, standard deviation; $\mathrm{AR}$, allelic richness (or mean number of alleles per locus); $\mathrm{AR}_{\mathrm{C}}$, allelic richness corrected for sample size; $H_{\mathrm{E}}$, expected heterozygosity; $H_{\mathrm{O}}$, observed heterozygosity; *a third white-headed duck haplotype was found among the sampled hybrids (Muñoz-Fuentes et al. 2005a); tincludes the Spanish ruddy ducks. 
Oxy

NewHybrids

$\begin{array}{lllllllllllllllllll}\mathrm{L} & \mathrm{P} & \mathrm{T} & \mathrm{E} & \mathrm{G} & \mathrm{R} & \mathrm{A} & \mathrm{M} & 1 & 3 & 6 & 10 & 11 & 13 & 15 & 17 & 19 & \text { mtDNA } & \text { Sex results }\end{array}$

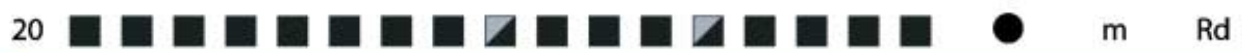

\begin{tabular}{|c|c|c|}
\hline 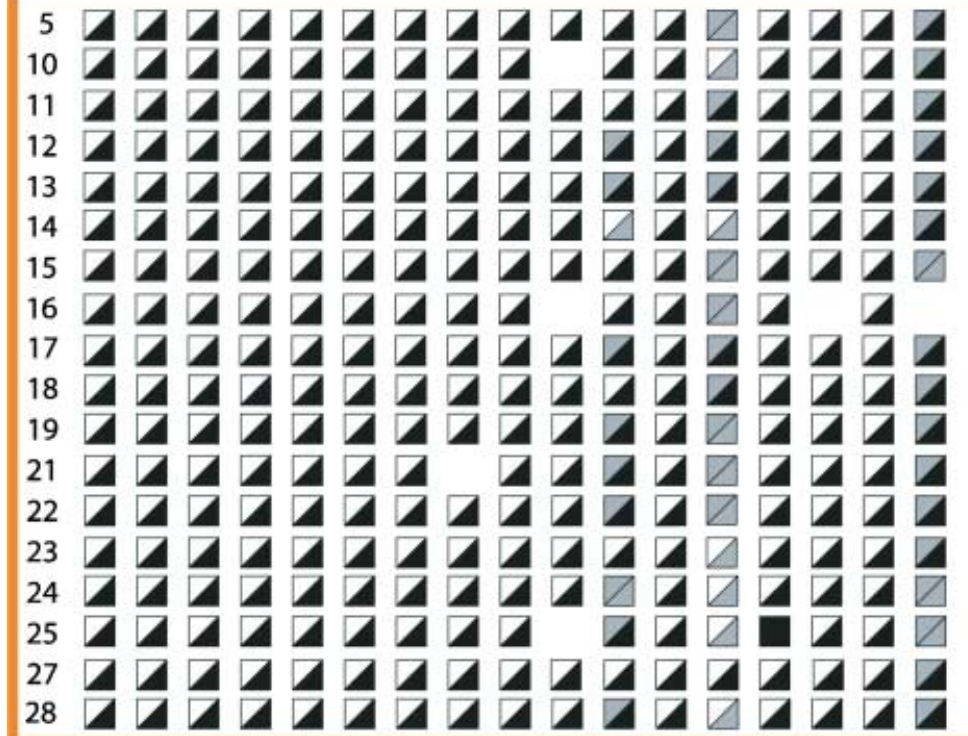 & $\begin{array}{l}f \\
m \\
f \\
m \\
m \\
f \\
m \\
f \\
m \\
m \\
m \\
? \\
m \\
m \\
f \\
f \\
f \\
m\end{array}$ & $\begin{array}{l}F 1 \\
F 1 \\
F 1 \\
F 1 \\
F 1 \\
F 1 \\
F 1 \\
F 1 \\
F 1 \\
F 1 \\
F 1 \\
F 1 \\
F 1 \\
F 1 \\
F 1 \\
F 1 \\
F 1 \\
F 1\end{array}$ \\
\hline
\end{tabular}

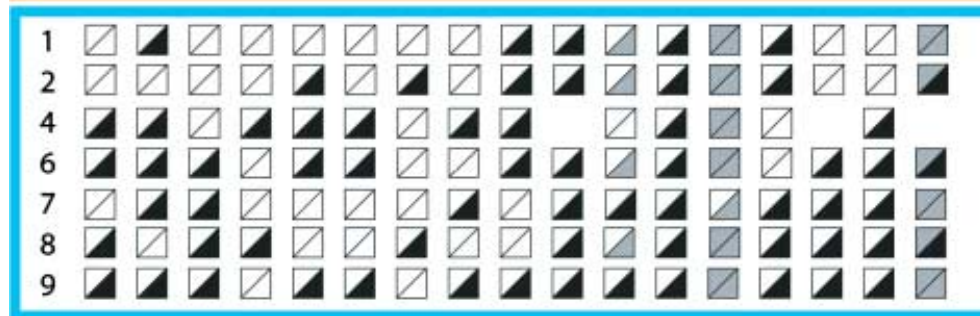

$\begin{array}{ll}\text { (1) } & m \\ \text { (1) } & m \\ \text { (2) } & m \\ \text { (2) } & m \\ \text { (1) } & m \\ \text { (1) } & f \\ \text { (1) } & m\end{array}$

Whd_BC

Whd_BC

Whd_BC

Whd_BC

Whd_BC

Whd_BC

3

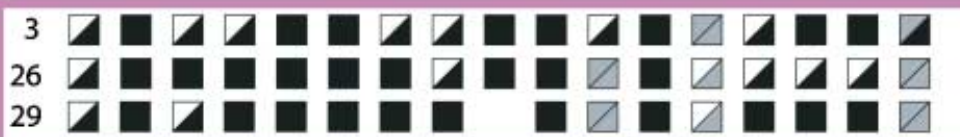
(2) $\mathrm{f}$ Whd_BC

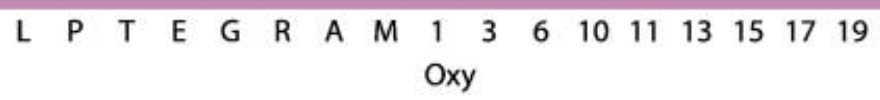

Fig. 2 Multilocus genotypes of individuals morphologically identified as hybrids. White and black indicate an allele (or haplotype) found in white-headed ducks or in ruddy ducks, respectively. Grey indicates an allele found both in white-headed ducks and ruddy ducks (this applies only to microsatellites as the intron markers represent fixed differences between the species). Capital letters and numbers stand for locus names of introns and microsatellites, respectively (see Material and methods and Table 1). Numbers inside the circles indicate the mtDNA haplotype found in that bird (1, Oleu_01; 2, Oleu_02; 3, Oleu_03 (Muñoz-Fuentes et al. 2005a); all feral European ruddy ducks carried the same haplotype, Ojam_01 (Muñoz-Fuentes et al. 2006)). Large coloured squares separate hybrid types based on results from the program NEWHYBRIDS. Sample ID numbers increase with collection date (1 being the earliest, 1993). Four individuals, marked with (a), were identified by NEWHYBRIDS as having a low to moderate probability of being second-generation backcrosses. Rd, ruddy duck; $\mathrm{F}_{1}$, first generation hybrid; Whd_Bc, progeny of $\mathrm{F}_{1} \times$ white-headed duck cross; Rd_Bc, progeny of $\mathrm{F}_{1} \times$ ruddy duck cross; $\mathrm{m}$, male; $\mathrm{f}$, female.

from each species (or, in a few cases, homozygous for a microsatellite allele present in both species) at all other loci; or in the case of individual 25, all but one other locus (see Fig. 2). Because allele 131 has not been previously observed in European ruddy ducks, these genotypes are highly unlikely. First, it is unlikely that a first generation backcross would have a genotype consistent with an $F_{1}$ hybrid at a sample of 16 loci but be homozygous for a species-specific allele at only one locus $(P=0.00014)$. Such a genotype is even less likely in a subsequent generation backcross. Second, it is highly unlikely to sample five different individuals that have this same pattern and which are all homozygous at the same locus $\left(P \approx 6 \times 10^{-20}\right)$. The above calculations assume that the white-headed duck allele (length 131) does not occur in Spanish ruddy ducks. If these genotypes were correct, then the sample 
of $F_{1}$ s would suggest a frequency of allele 131 in Spanish ruddy ducks of $5 / 18=0.278$, but this allele was not detected among 27 Spanish ruddy ducks (nor in a larger sample of 48 ruddy ducks from other localities in Europe (Muñoz-Fuentes et al. 2006)). The probability of not detecting an allele of frequency 0.278 in a sample of this size is $P \approx 1.5 \times 10^{-30}$. All evidence therefore suggests that these results are due to preferential amplification of whiteheaded duck alleles in some hybrid individuals. This marker was isolated from a white-headed duck clone and variation among ruddy ducks in one of the primer regions perhaps makes amplification of certain ruddy duck alleles difficult, especially when there is a white-headed duck allele present that can be more easily amplified. We therefore excluded this locus from the following analysis.

Among the 29 putative hybrids collected in Spain, 17 carried one ruddy duck allele and one white-headed duck allele at each locus and were therefore first-generation $\left(\mathrm{F}_{1}\right)$ hybrids. An eighteenth bird (individual 25, Fig. 2) was heterozygous at all but one locus (this sample was reanalysed and the same result obtained) and also was most likely an $F_{1}$ hybrid. This multilocus genotype is highly improbable for other hybrid classes (e.g. $F_{2}$ or backcrosses), suggesting that a recent mutation, rare allele, or genotyping error accounts for the single homozygous locus in this individual. A single individual (individual 20, Fig. 2) had ruddy duck alleles at all loci and was apparently misidentified as a hybrid due to its unusual morphology (completely black head and unusual bill shape). The remaining 10 individuals had a mixture of homozygous and heterozygous loci and therefore represented subsequent generation hybrids produced by backcrossing to one or the other parental species or mating between hybrid individuals. We assigned these individuals to hybrid categories using the Bayesian analysis software NEWHYBRIDS (Anderson \& Thompson 2002). The software assigned morphologically identified white-headed ducks and ruddy ducks to their respective species, and among the putative hybrids identified one pure ruddy duck, $18 \mathrm{~F}_{1}$ s and 10 backcrosses. All assignments were with a probability of $98 \%$ or higher, except one hybrid (individual 9, Fig. 2) which was assigned to a white-headed duck backcross with a probability of $67 \%$ and an $\mathrm{F}_{1}$ hybrid with a probability of $32 \%$. Seven of the 10 backcrosses had genotypes expected from the backcrossing of $F_{1}$ hybrids to white-headed ducks, whereas three were produced by backcrosses to ruddy ducks.

Based on mtDNA, which is maternally inherited, our data also allowed inferences about the direction of interspecific matings. The majority $(89 \%)$ of $\mathrm{F}_{1}$ hybrids $(n=18)$ had ruddy duck mtDNA, implying that most crosses were between female ruddy ducks and male white-headed ducks (Fig. 2). In contrast, the 10 remaining hybrid individuals resulting from backcrosses to either white-headed ducks or ruddy ducks all had white-headed duck mtDNA.

\section{Discussion}

The native white-headed duck and the introduced ruddy duck

Substantial divergence in mtDNA control region sequences and fixed differences between white-headed ducks and ruddy ducks across multiple nuclear introns support the conclusion that they are distinct species (Livezey 1995; McCracken et al. 2000; McCracken \& Sorenson 2005). Indeed, the two species are not each other's closest relatives and their most recent common ancestor dates to perhaps 2 million years ago (McCracken \& Sorenson 2005). These results negate suggestions in the popular media that white-headed ducks and ruddy ducks are not distinct species (see McCracken et al. 2000).

Based on a sample of 10 microsatellite loci, including five obtained from each species, we found that white-headed ducks had lower genetic diversity than the introduced ruddy duck population in Europe. This result is particularly striking considering that the European ruddy duck population apparently derives from just seven founders (Hudson 1976; Muñoz-Fuentes et al. 2006). Rapid population growth following the founding event likely minimized genetic drift and the loss of genetic diversity in ruddy ducks (Muñoz-Fuentes et al. 2006), whereas a severe bottleneck following a long period of declining population size resulted in a greater reduction in genetic diversity in white-headed ducks. Loss of genetic diversity compromises a species evolutionary potential and increases extinction risk (Frankham et al. 2002).

\section{Morphological and genetic identification of parental species and hybrids}

All individuals identified either as ruddy ducks or hybrids during the control programme were confirmed to be such genetically, except for one individual (individual 20, see Figs 1 and 2). Hybrid identification during the control programme followed a key based on morphological criteria such as plumage characteristics and beak shape (Urdiales \& Pereira 1993), which performed well in identifying hybrids, but failed to identify different hybrid categories (unpublished data).

Individual 20 (Figs 1 and 2) had a phenotype generally similar to a ruddy duck, but with a completely black head and unusual bill shape and was, due to its unusual characteristics, misidentified as a hybrid. Genetic analysis indicated it to be a ruddy duck, with a 'unique' microsatellite allele, not found in any other ruddy duck, either in Europe or North America ( $n=142$ ) (Muñoz-Fuentes et al. 2006), or in white-headed ducks. It is highly unlikely that all of the remaining microsatellite alleles and nuclear introns would match a ruddy duck genotype if this bird were not a ruddy 
duck. Therefore, we conclude that this bird is a ruddy duck with variant plumage.

\section{Hybridization in the wild}

Microsatellite markers and fixed differences in nuclear introns allowed us to differentiate among first-generation hybrids, the progeny of backcrossing, and pure ruddy ducks and white-headed ducks. Our results demonstrate that first generation hybrids are fertile and mate with individuals of both parental species in the wild. It is possible that our sample of hybrids includes some siblings, but based on sampling dates and localities (see Table S5, Supplementary material), and mtDNA haplotypes (Fig. 2), the individuals identified as backcross progeny were produced in at least two and three independent backcrosses to ruddy ducks and white-headed ducks, respectively. Therefore, backcrossing is not an isolated phenomenon.

Because the majority $(89 \%)$ of $\mathrm{F}_{1}$ hybrids had ruddy duck mtDNA, most crosses were between female ruddy ducks and male white-headed ducks. This strong asymmetry in the direction of hybridization is likely a consequence of the efficiency of the eradication programme in eliminating male ruddy ducks (males of the two species are easier to differentiate than females), rather than a behavioural asymmetry in the biology of hybridization (Green \& Hughes 2001). This effect, however, has likely changed through time: the proportion of females among culled ruddy ducks and hybrids was significantly greater from June 2000 to May 2003, when the control team became nationally coordinated and its effectiveness presumably increased, than from June 1991 to May 2000 ( $\chi^{2}=2.9$ for the change of sex ratios between the two periods, $P<0.05$; Calzada et al. 2003).

A contrasting pattern was observed among individuals identified as the progeny of subsequent generation backcrosses to one of the two parental species. All 10 of these individuals had white-headed duck mtDNA (Fig. 2). Thus, our data provide no evidence of reproduction by $\mathrm{F}_{1}$ females with ruddy duck mtDNA, even though most $\mathrm{F}_{1}$ hybrids had ruddy duck mtDNA. In contrast, the three individuals produced by backcrosses to ruddy ducks had white-headed duck mtDNA, indicating that female hybrids with white-headed duck mtDNA are fertile and successfully reproduced with male ruddy ducks. Likewise, seven individuals that resulted from $\mathrm{F}_{1} \mathrm{~s}$ backcrossing with white-headed ducks had white-headed duck mtDNA. These individuals may have been produced by either a female white-headed duck mating with a male hybrid or a female hybrid with white-headed duck mtDNA mating with a male white-headed duck.

The production of ruddy duck backcrosses with whiteheaded duck mtDNA demonstrates conclusively that female hybrids with white-headed duck mtDNA are fertile, whereas direct evidence that female hybrids with ruddy duck mtDNA are fertile is still lacking. Again, this result contrasts with the preponderance of ruddy duck mtDNA among our sample of $F_{1}$ hybrids. Thus, in accord with Haldane's rule (in birds, females are heterogametic) and as observed in other birds (Price \& Bouvier 2002), hybrid females with ruddy duck mtDNA may have low fertility or are perhaps infertile. Alternatively, given our relatively small sample of hybrids, the absence of subsequent generation hybrids with ruddy duck mtDNA may be due to chance. Future research on ruddy ducks and white-headed ducks should test for hybrid infertility due to genomic incompatibilities that depend on the direction of the cross (Orr 1997; Price \& Bouvier 2002).

\section{Conservation implications}

Although we detected backcrossing between hybrids and white-headed ducks (Fig. 2), we found no evidence of ruddy duck alleles in individuals that were morphologically identified as white-headed ducks $(n=63$ using microsatellite data, including 43 for which we also gathered intron data). Based only on our intron data, for which there are no alleles shared between the two species, and given that none of the 43 birds identified as white-headed ducks had any ruddy duck alleles at a total of eight loci, the $95 \%$ confidence interval on the proportion of ruddy duck genes in the white-headed duck population ( 0 of 688 typed alleles, i.e. 43 individuals $\times 8$ loci $\times 2$ alleles per locus) is $0-0.7 \%$. Likewise, the $95 \%$ confidence interval on the proportion of white-headed ducks that have one or more ruddy duck alleles at one or more of the loci we typed ( 0 of 63 birds typed) is $0-6 \%$. Thus, the continuing ruddy duck eradication programme in Spain has apparently been effective in limiting introgression to date. Our results, however, are alarming: despite an aggressive control programme in place since 1991, backcrosses to both parental species have been found in Spain. These results suggest that there would be a significant risk of widespread introgression if this programme is not continued, and particularly if ruddy ducks' numbers keep increasing in other parts of Europe. In addition, the situation may be exacerbated by the competitive asymmetry between the expanding population of an invasive species and a recovering native species with greatly reduced genetic diversity. If left to proceed without control, hybridization and expansion of the ruddy duck will likely cause the loss of species-specific characters and adaptations in white-headed ducks and eventually threaten the species with extinction. Alternatively, the result may be a hybrid swarm as recorded in New Zealand as a result of mallard and grey duck, hybridization (Gillespie 1985; Rhymer et al. 1994).

The fact that we did not detect ruddy duck alleles in white-headed ducks indicates that introgression, if it has 
occurred, remains at low frequency and that there is still time to prevent the extinction of the white-headed duck through hybridization. The maintenance of the whiteheaded duck's genetic integrity will depend on the continued success of a programme for the elimination of hybrids and ruddy ducks. In the absence of a ruddy duck eradication programme, as now implemented in the UK, France and Spain, it is likely that patterns of hybridization might be different. In the UK, the main source population of ruddy ducks in Europe, growth rate is estimated at $18 \%$ per annum and the number of countries in which the ruddy duck has been recorded since first breeding in the wild in the UK in 1960 is increasing (Hughes et al. 2004). If both the white-headed duck and ruddy duck are to be preserved, these species cannot co-exist in the same areas and action against the ruddy duck in Europe should be intensified, especially in the UK. The plight of the Spanish white-headed duck exemplifies how human actions in one country can have dramatic trans-boundary effects, how different perturbations can act synergistically to decrease the chances of long-term survival for wild species, and how coordinated international conservation plans are needed for effective biodiversity conservation.

\section{Acknowledgements}

The following people provided samples for this study: B. Hughes, C. Gerique, C. Gutiérrez, C. Perennou, C. Sánchez, C. Urdiales, G. Vaschetti, H. Garrido, I. Henderson, J. A. Torres, J. L. Echevarrías, J. Peters, K. G. McCracken, L. Barbier, M. Ferrández, M. Panayotopoulou, N. Jarrett, O. K. Nielsen, P. Pereira, R. B. Brua and R. Cromie. This study was funded by La Consejería de Medio Ambiente de la Junta de Andalucía, Spain, a fellowship by the Spanish Ministry of Education and by the Spanish Research Council (CSIC) to V.M.F., a National Science Foundation grant to M.D.S., and a grant by the Swedish Research Council for Environment, Agricultural Sciences and Spatial Planning to C.V.

\section{Supplementary material}

The supplementary material is available from http://www.blackwellpublishing.com/products/journals/ suppmat/MEC/MEC3170/MEC3170sm.htm

Table S1 Primer names and sequences used in this study to amplify and sequence introns at the loci indicated. An asterisk following the locus name designates loci not selected for genotyping hybrids because either amplification or sequencing was unsuccessful, or there were no species-diagnostic differences.

Table S2 Allele frequencies at 10 microsatellite loci in whiteheaded ducks by population (Spain, Greece, captive) and feral ruddy ducks from Spain. Sample size $(n)$ is indicated below the population name. Locus names are in bold and alleles are in italics, designated by their size in base pairs. For white-headed ducks, private alleles (present only in one population) appear in bold. Acebuche stands for the captive population sampled from El Acebuche in Doñana National Park, Spain, established before hybridization was detected in Spain. The small number of alleles shared between ruddy ducks and white-headed ducks in Spain were also shared between allopatric populations of both species. Alleles marked with ${ }^{*}$ ) were observed in ruddy ducks from North America (Muñoz-Fuentes et al. 2006), but in Europe were found only in white-headed ducks.

Table S3 Probabilities that each individual belongs to a given hybrid category as estimated by NEWHYBRIDS.

Table S4 Variable nucleotide positions in mtDNA control region sequences of white-headed ducks and ruddy ducks in Europe (1993-2003). Eighteen fixed differences between the two species are marked with asterisks. Total number of sites is $576 ;$;.' denotes an identical base and ' - ' an indel.

Table S5 Hybrid samples used in this study. Sample ID, collection date, origin and age for each hybrid individual are provided, as well as the corresponding number code used in the main text. ad, adult; juv, juvenile.

\section{References}

Anderson EC, Thompson EA (2002) A model-based method for identifying species hybrids using multilocus genetic data. Genetics, 160, 1217-1229.

Belkhir K, Borsa P, Chikhi L, Raufaste N, Bohomme F (1996-2004) GENETIX 4.05, logiciel sous Windows TM pour la génétique des populations. Laboratoire Génome, Populations, Interactions, CNRS UMR 5000, Université de Montpellier II, Montpellier, France.

BirdLife International (2000) Threatened Birds of the World. Lynx Edicions and BirdLife International, Barcelona, Spain, and Cambridge, UK.

Browne RA, Griffin CR, Chang PR, Hubley M, Martin AE (1993) Genetic divergence among populations of the Hawaiian duck, Laysan duck, and mallard. Auk, 110, 49-56.

Brua RB (2001) Ruddy Duck (Oxyura jamaicensis). In: Birds of North America, No. 696 (eds Poole A, Gill F). The Birds of North America, Inc., Philadelphia, Pennsylvania.

Calzada J, Andrés T, Bravo MA et al. (2003) Control de la malvasía canela en España. In: Primer Congreso Nacional Sobre Especies Exóticas Invasoras. León, Spain.

Collier MP, Banks AN, Austin GE, Girling T, Hearn RD, Musgrove AJ (2005) The Wetland Bird Survey 2003/04: Wildfowl and Wader Counts. BTO/WWT/RSPB/JNCC, Thetford, UK.

Coyne JA, Orr HA (2004) Speciation. Sinauer and Associates, Sunderland, Massachusetts.

Ellegren H, Primmer CR, Sheldon BC (1995) Microsatellite evolution - directionality or bias. Nature Genetics, 11, 360-362.

Frankham R, Ballou JD, Briscoe DA (2002) Introduction to Conservation Genetics. Cambridge University Press, Cambridge, UK.

Friesen VL, Congdon BC, Walsh HE, Birt TP (1997) Intron variation in marbled murrelets detected using analyses of single-stranded conformational polymorphisms. Molecular Ecology, 6, 1047-1058.

Gillespie GD (1985) Hybridization, introgression and morphometric differentiation between mallard Anas platyrhynchos and grey duck Anas superciliosa in Otago, New Zealand. Auk, 102, 459-469.

Grant PR, Grant BR (1992) Hybridization of bird species. Science, 256, 193-197.

Green AJ, Hughes B (2001) Oxyura leucocephala white-headed duck. BWP Update, 3, 79-90. 
Hudson R (1976) Ruddy ducks in Britain. British Birds, 69, 132-143.

Hughes B (1997) Oxyura jamaicensis ruddy duck. In: The EBCC Atlas of European Breeding Birds: Their Distribution and Abundance (eds Hagemeijer WJM, Blair MJ). T \& AD Poyser, London, UK.

Hughes B, Robinson JA, Green AJ, Li ZWD, Mundkur TC (2004) International Single Species Action Plan for the White-headed Duck Oxyura leucocephala. The Wildfowl and Wetlands Trust, Slimbridge, Gloucester, UK.

Kalinowski ST (2005) HP-RARE 1.0: a computer program for performing rarefaction on measures of allelic richness. Molecular Ecology Notes, 5, 187-189.

Kanda N, Leary RF, Spruell P, Allendorf FW (2002) Molecular genetic markers identifying hybridization between the Colorado river-greenback cutthroat trout complex and Yellowstone cutthroat trout or rainbow trout. Transactions of the American Fisheries Society, 131, 312-319.

Kulikova IV, Zhuravlev YN, McCracken KG (2004) Asymmetric hybridization and sex-biased gene flow between eastern spotbilled ducks (Anas zonorhyncha) and mallards (A. platyrhynchos) in the Russian far east. Auk, 121, 930-949.

Li ZWD, Mundkur T (2003) Status Overview and Recommendation for Conservation of the White-Headed Duck Oxyura Leucocephala in Central Asia. Wetlands International Global Series 15, Kuala Lumpur, Malaysia.

Liou LW, Price TD (1994) Speciation by reinforcement of premating isolation. Evolution, 48, 1451-1459.

Livezey BC (1995) Phylogeny and comparative ecology of stiff-tailed ducks (Anatidae, Oxyurini). Wilson Bulletin, 107, 214-234.

Mank JE, Carlson JE, Brittingham MC (2004) A century of hybridization: decreasing genetic distance between American black ducks and mallards. Conservation Genetics, 5, 395-403.

McCracken KG, Sorenson MD (2005) Is homoplasy or lineage sorting the source of incongruent mtDNA and nuclear gene trees in the stiff-tailed ducks (Nomonyx-Oxyura)? Systematic Biology, 54, 35-55.

McCracken KG, Harshman J, Sorenson MD, Johnson KP (2000) Are ruddy ducks and white-headed ducks the same species? British Birds, 93, 394-398.

McCracken KG, Johnson WP, Sheldon FH (2001) Molecular population genetics, phylogeography, and conservation biology of the mottled duck (Anas fulvigula). Conservation Genetics, 2, 87-102.

Moody ML, Less DH (2002) Evidence of hybridity in invasive watermilfoil (Myriophyllum) populations. Proceedings of the National Academy of Sciences, USA, 99, 14867-14871.

Muñoz-Fuentes V, Green AJ, Negro JJ, Sorenson MD (2005a) Population structure and loss of genetic diversity in the endangered white-headed duck, Oxyura leucocephala. Conservation Genetics, 6, 999-1015.

Muñoz-Fuentes V, Gyllenstrand N, Negro JJ, Green AJ, Vilà C (2005b) Microsatellite markers for two stifftail ducks: the white-headed duck, Oxyura leucocephala, and the ruddy duck, O. jamaicensis. Molecular Ecology Notes, 5, 263-265.

Muñoz-Fuentes V, Green AJ, Sorenson MD, Negro JJ, Vilà C (2006) The ruddy duck Oxyura jamaicensis in Europe: natural colonization or human introduction? Molecular Ecology, 15, 1441-1453.

Orr HA (1997) Haldane's rule. Annual Review of Ecology and Systematics, 28, 195-218.

Pacheco NM, Congdon BC, Friesen VL (2002) The utility of nuclear introns for investigating hybridization and genetic introgression: a case study involving Brachyramphus murrelets. Conservation Genetics, 3, 175-182.
Price TD, Bouvier MM (2002) The evolution $\mathrm{F}_{1}$ postzygotic incompatibilities in birds. Evolution, 56, 2083-2089.

Primmer CR, Borge T, Lindell J, Sætre GP (2002) Single-nucleotide polymorphism characterization in species with limited available sequence information: high nucleotide diversity revealed in the avian genome. Molecular Ecology, 11, 603-612.

Raymond M, Rousset F (1995) GENEPOP (version 1.2): population genetics software for exact tests and ecumenicism. Journal of Heredity, 86, 248-249.

Rhymer JM, Williams MJ, Braun MJ (1994) Mitochondrial analysis of gene flow between New Zealand mallards (Anas platyrhynchos) and grey ducks (A. superciliosa). Auk, 111, 970-978.

Rice WR (1989) Analysing tables of statistical tests. Evolution, 43, 223-225.

Sorenson MD, Fleischer RC (1996) Multiple independent transpositions of mitochondrial DNA control region sequences to the nucleus. Proceedings of the National Academy of Sciences, USA, 93, 15239-15243.

Torres JA, Moreno-Arroyo B (2000a) La recuperación de la malvasía cabeciblanca (Oxyura leucocephala) en España durante el último decenio del siglo XX. Oxyura, 10, 5-51.

Torres JA, Moreno-Arroyo B (2000b) Presencia de la malvasía canela (Oxyura jamaicensis) en España. Oxyura, 10, 69-78.

Urdiales C, Pereira P (1993) Claves de identificación de O. jamaicensis, O. leucocephala y sus híbridos. Instituto Nacional para la Conservación de la Naturaleza (ICONA), Madrid, Spain.

Vähä JP, Primmer CR (2006) Efficiency of model-based Bayesian methods for detecting hybrid individuals under different hybridization scenarios and with different numbers of loci. Molecular Ecology, 15, 63-72.

Van Oosterhout C, Hutchinson WF, Wills DPM, Shipley P (2004) MICRO-CHECKER: software for identifying and correcting genotyping errors in microsatellite data. Molecular Ecology Notes, 4, 535-538.

Williams CL, Brust RC, Fendley TT, Tiller GR, Rhodes OE (2005) A comparison of hybridization between mottled ducks (Anas fulvigula) and mallards (A. platyrhynchos) in Florida and South Carolina using microsatellite DNA analysis. Conservation Genetics, 6, 445-453.

Wright TF, Johns PM, Walters JR, Lerner AP, Swallow JG, Wilkinson GS (2004) Microsatellite variation among divergent populations of stalk-eyed flies, genus Cyrtodiopsis. Genetical Research, 84, 27-40.

Violeta Muñoz is interested in conservation genetics and evolutionary ecology of vertebrate species, and deals with questions in these fields using molecular biology techniques. Carles Vilà research interests include conservation genetics of diverse groups of vertebrates as well as the study of the process of mammal domestication. Andy Green has extensive experience researching the ecology and conservation biology of Oxyura and other waterfowl; he has a broad interest in aquatic ecology, especially the functional role of waterbirds. Juan José Negro is an evolutionary ecologist with an interest in genetic variability issues affecting small populations; he also carries out research on the evolution and mechanisms of plumage patterns and colours. Michael Sorenson has long-standing interests in the systematics and behavioural ecology of waterfowl and has in recent years been working on a comprehensive molecular phylogeny for the group. 